\title{
Congenital neurocristic tumor presenting as an isolated calvarial defect in an infant: case report
}

\author{
Caroline Hadley, BS, ${ }^{1}$ Carrie A. Mohila, MD, PhD, ${ }^{2}$ Thomas G. Luerssen, MD, ${ }^{1}$ and Sandi Lam, MD1 \\ Departments of ${ }^{1}$ Neurosurgery and ${ }^{2}$ Pathology, Texas Children's Hospital, Baylor College of Medicine, Houston, Texas \\ In infants, the presence of a cranial defect may be due to a variety of traumatic, inflammatory, neoplastic, and congenital \\ abnormalities. Differentiation between these possible etiologies is facilitated by clinical presentation, patient history, \\ and physical examination. Congenital cutaneous neural crest-derived lesions are unlikely to be considered in a patient \\ presenting with an asymptomatic cranial defect without overlying mass or skin pigmentation. The authors present an \\ unusual case of a 2-month-old infant with an asymptomatic calvarial defect with normal overlying skin. Pathology of \\ the excised tissue showed features consistent with a congenital neurocristic tumor: a pigmented, neural crest-derived \\ hamartomatous tumor that typically presents as a melanotic skin lesion.
}

http://thejns.org/doi/abs/10.3171/2014.12.PEDS14497

KEY WORDS calvarial lesion; neurocristic; lytic bone lesion; skull defect; pediatric; infant; oncology

T YTIC lesions of the calvaria in pediatric patients carry a broad differential diagnosis, including congenital, traumatic, inflammatory, infectious, and neoplastic lesions. ${ }^{9}$ In young children, this differential diagnosis includes Langerhans cell histiocytosis, osteomyelitis, metastasis, epidermoid cyst, intraosseous hemangioma, fibrous dysplasia, and congenital defects such as aplasia cutis congenital and foramina parietalia permagna ${ }^{4,7,9,11}$ Disrupted neural tube closure and abnormal ossification may also be considered..$^{29}$ Many of these lytic bone lesions can present with an associated overlying expansile soft-tissue mass, without changes to the overlying skin.

Cutaneous lesions of the scalp may present with similar soft-tissue masses but, unlike the lesions mentioned above, are not typically associated with abnormalities of the underlying bone. ${ }^{25}$ Cutaneous neurocristic tumors are a heterogeneous group of neuroectodermally derived lesions and include neurocristic cutaneous hamartomas (NCHs) and malignant neurocristic tumors. These lesions clinically present with a pigmented macular or plaque-like lesion of the scalp with associated soft-tissue mass. ${ }^{19,24,26} \mathrm{We}$ present an unusual case of a subgaleal congenital $\mathrm{NCH}$ in an infant presenting with a skull defect without an associated pigmented skin lesion. To our knowledge, this constellation of findings has not been previously described in the literature.

\section{Case Report}

History and Examination

This otherwise healthy and developmentally normal 2-month-old full-term male infant was born following an uncomplicated pregnancy and delivery. On presentation, the patient had a persistent palpable painless calvarial defect over the left lambdoid suture, $3 \mathrm{~cm}$ off midline, which was initially thought by his caregivers to be an eccentric posterior fontanelle. The overlying skin and hair were normal. Since this was an unusual large bony defect, imaging was performed for evaluation. CT scanning confirmed a $4.1 \times 3.0-\mathrm{cm}$ bone defect involving the parietal and occipital bones with an overlying $4.1 \times 0.6-\mathrm{cm}$ soft-tissue mass (Fig. 1). There was no intracranial extension, and the findings from CT scanning of the head were otherwise normal. 
Based on the radiological findings, the differential diagnosis for this lytic skull lesion included neuroblastoma and Langerhans cell histiocytosis. Systemic workup revealed no other lesions on skeletal survey and imaging, and only mild elevation in bilirubin and lactate dehydrogenase levels were found on laboratory investigation. The defect persisted at short-interval follow-up. Surgery was undertaken for diagnosis after obtaining multidisciplinary input.

\section{Operative Findings}

There was an abnormal subgaleal soft-tissue lesion disrupting the periosteum, interdigitating with the bony edges of the calvaria and adherent to the dura. The mass was rubbery, lobulated, and light purple to tan. The bone edges were curetted until normal bone remained. All visible abnormal tissue was excised, and the dura remained intact. Repair of the skull defect was not necessary because of the patient's young age. The child tolerated surgery well. The wound was well healed at postoperative follow-up with progressive decrease in size of the skull defect over 6 months.

\section{Pathological Findings}

Histological evaluation of the excised specimen revealed a spindle cell tumor with a plexiform architecture and infiltrative growth including invasion of bone (Fig. 2A). In areas, the tumor cells showed a loose whorled arrangement around blood vessels (Fig. 2B). Other foci showed prominent Meissner's corpuscle-like neural structures, which were strongly S100 positive (Fig. 2C and D). A few scattered melanin-containing dendritic cells with immunoreactivity for S100 and HMB-45 were also present within the tumor (Fig. 2E). Background spindle cells were variably immunoreactive for smooth-muscle actin (Fig. 2F). Histiocytes and giant cells were scattered throughout the tumor. There were no areas of necrosis, and only rare mitotic figures were identified. Additional immunohistochemical studies revealed that the tumor cells were negative for CD1a and CD207, excluding Langerhans cell histiocytosis, and for myogenin and muscle-specific actin, ruling out a rhabdomyosarcomatous component of the lesion. Electron microscopy revealed absence of basal lamina and tight junctions, excluding a meningioma. Chromo-
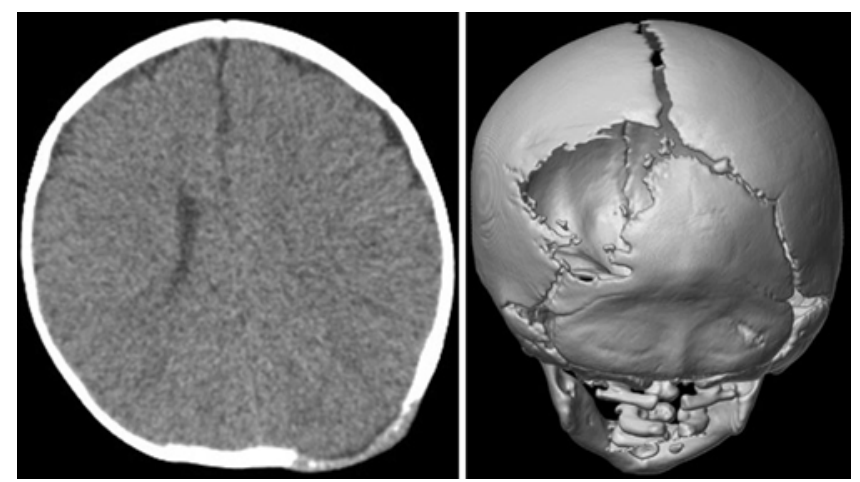

FIG. 1. Left: Noncontrast axial CT scan showing the lytic bone lesion. Right: 3D CT reconstruction showing a $4.1 \mathrm{~cm} \times 3.0-\mathrm{cm}$ defect in the left parietooccipital region involving the left lambdoid suture.
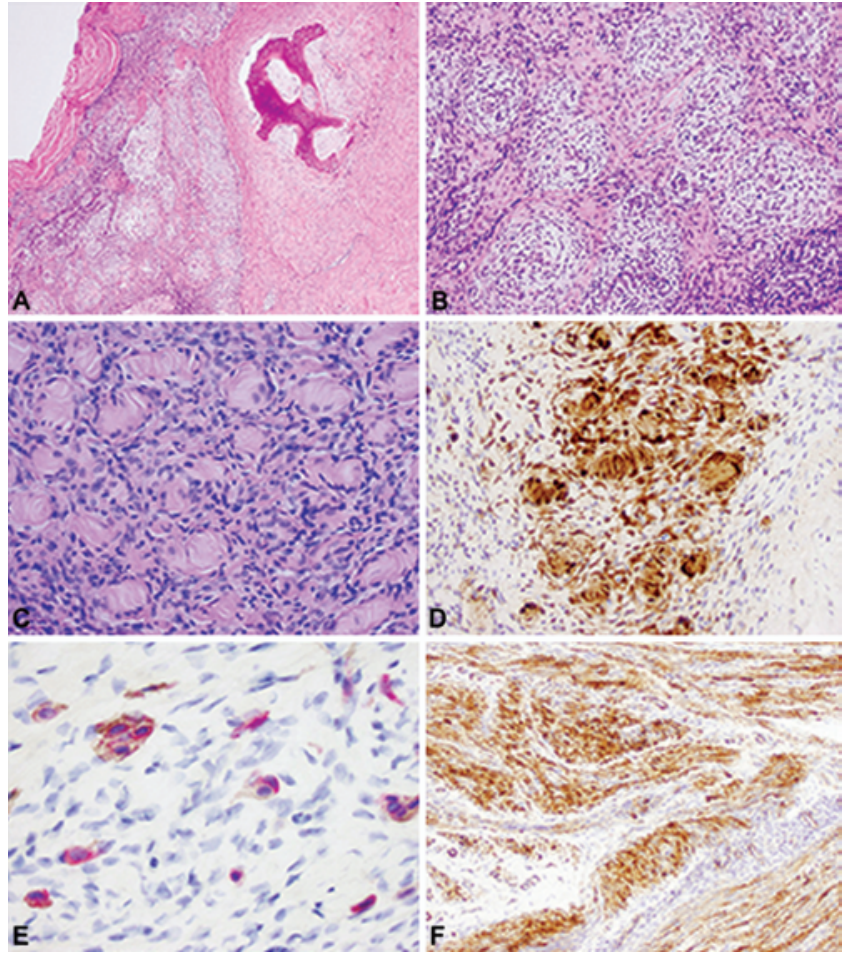

FIG. 2. Photomicrographs of the congenital neurocristic hamartoma. A: A plexiform architecture with nodules of spindle cells invading bone and soft tissue is shown. B: Many spindled tumor cells are arranged around blood vessels. C and D: Structures resembling Meissner's corpuscles are prominent $(\mathrm{C})$ and positive for $\mathrm{S} 100$ by immunohistochemistry (D). E: Pigmented dendritic cells are HMB-45 immunoreactive. F: Fascicles of spindle cells show smooth-muscle actin immunoreactivity. $H \& E(A-C)$; original magnification $\times 40(A), \times 100(B), \times 200(C, D$, and $F)$, and $\times 400(E)$. Figure is available in color online only.

some analysis revealed a normal male karyotype. Based on these findings, the tumor was judged to be a congenital pigmented neurocristic tumor.

\section{Discussion}

Abnormal migration and growth of neural crest cells during development can result in benign and malignant childhood tumors. ${ }^{3}$ Several of these lesions can be identified in the skull, including melanotic neuroectodermal tumors of infancy (MNTIs), cellular blue nevi (CBNs), and NCHs. ${ }^{1,3,26}$ These entities vary in gross and histological findings, growth rate, potential for malignancy, and age at presentation. ${ }^{11,12,27}$ Efforts to characterize and differentiate these congenital cutaneous lesions have been driven by attempts to identify the potential for future malignancy; currently the risk associated with each type is not well known. ${ }^{6,12,13,17,19}$ We review this spectrum to highlight differences in these heterogeneous group of lesions.

NCHs are rare cutaneous tumors with descriptions limited to case reports and small case series. They are most commonly observed in the scalp and can be congenital or acquired..$^{19}$ These tumors typically present later in childhood and more commonly in adulthood, which is likely due to slower progression of the lesion., ${ }^{1,212,21}$ Skin overlying these lesions is grossly pigmented and alopecic. ${ }^{19,25}$ 
These lesions typically involve the dermis and subcuticular layers of the skin and are nodular and infiltrative. ${ }^{17}$ Histologically, they are composed of cells of melanocytic, neural, and mesenchymal differentiation. ${ }^{12,26}$ Key histological features include proliferation of different cell types thought to be derived from neural crest origin, such as nevomelanocytes, Schwann-like cells, and pigmented spindled and dendritic cells.,13,19,21,24 If these lesions display a prominent melanocytic component, they can be difficult to differentiate from other pigmented cutaneous abnormalities, such as congenital nevi, as there can be some histological overlap. ${ }^{17,24}$ This overlap in histological findings has led some to suggest that pigmented cutaneous nevi with neural crest components represent a spectrum of lesions, rather than distinct entities..$^{17,24}$

Unlike an NCH, an MNTI presents as a solitary pigmented expansile mass appearing in the 1st year of life. They most commonly occur in the maxilla, although they may also appear in other craniofacial bones. These lesions may be locally aggressive but are generally classified as benign. ${ }^{10,20}$ However, the potential for future malignancy cannot be ruled out or predicted based on histological features or clinical progression. ${ }^{10}$ Histologically, MNTIs are biphasic tumors composed of nests of large melanin-containing epithelioid cells and small neuroblastic cells set within a fibrous stroma. ${ }^{11,20}$ MNTIs may share some histological features with $\mathrm{NCHs}$, such as melanin-containing cells, but they differ in that they do not have a differentiated neural component, are generally locally aggressive, and typically involve the craniofacial soft tissues, whereas $\mathrm{NCHs}$ most commonly occur on the scalp. ${ }^{24}$

A CBN is another related entity and is clinically identified by a blue raised lesion, most commonly found in the sacrococcygeal region. ${ }^{22}$ These lesions may be congenital or appear in early childhood and are typically slow growing. Grossly they are well circumscribed, localized to the dermis, and may be nodular or lobulated. Involvement of large nerve fibers is not uncommon..$^{17,22}$ Histologically, CBNs are composed of spindle cell nodules interspersed with regions resembling blue nevi, with dendritic melanocytes and surrounding desmoplastic reaction. CBN pigmentation and degree of sclerosis are variable. ${ }^{16,22}$ These lesions lack the divergent differentiation of $\mathrm{NCHs} .{ }^{17}$

The clinical presentation of the present case of a congenital $\mathrm{NCH}$ is unique compared with previous reports in the literature. Typically, an $\mathrm{NCH}$ presents with an enlarging pigmented skin lesion. Our patient presented with a palpable calvarial defect in the parietooccipital region with normal-appearing overlying skin. There was no suspicion or known indication for skin biopsy at the time of surgery; thus, we cannot comment on any histological changes in the overlying epidermis or dermis.

The present case also differs from those in the literature in that cutaneous lesions of neural crest origin do not commonly involve the underlying bone. While some cranial pigmented lesions with associated calvarial defects have been described, they have been of histologically nevoid type and have presented as large, grossly pigmented lesions. ${ }^{8,14-16,18,23,28}$ There have been 7 reports in the literature of CBNs with an associated calvarial defect, 6 of which were in the pediatric population. ${ }^{8,14-16,18,23,28}$ In all of these cases, the lytic skull lesion was associated with a prominent pigmented lesion of the overlying skin. Two reported congenital neurocristic lesions involved bone. One case of $\mathrm{NCH}$ displayed bone marrow infiltration in the posterior skull without an associated lytic defect. ${ }^{5}$ Another case of reported malignant neurocristic tumor involved the occipital bone and infiltrated the dermis, subcutaneous tissue, and parotid gland. ${ }^{21}$ Both of these lesions presented with the primary finding of an overlying enlarging pigmented skin lesion.

To our knowledge, this is the first report of an $\mathrm{NCH}$ presenting without an overlying pigmented cutaneous lesion. In addition, this case represents the third reported case of an $\mathrm{NCH}$ involving the skull bone. Our findings here suggest that neurocristic lesions may have a broader clinical presentation than previously described and should be considered in the differential diagnosis for lytic skull lesions in infants and young children. As with other congenital lesions of neural crest origin, including CBNs and MNTIs, vigilant long-term follow-up is warranted. The risk for latent malignancy cannot be predicted based on clinical or histological features. Because the malignancy potential of many of these neurocristic lesions is unknown, recognizing that a lytic skull lesion may have a neurocristic origin is important in surgical planning and long-term surveillance.

\section{Acknowledgments}

We thank Dr. Sharon Weiss for reviewing this case in consultation and Karen Prince for assistance with figure preparation.

\section{References}

1. Baskara A, Sapanara N, Medvetz L: Giant neurocristic hamartoma of scalp: a case report. Grand Rounds 10:91-94, 2010

2. Bevona C, Tannous Z, Tsao H: Dermal melanocytic proliferation with features of a plaque-type blue nevus and neurocristic hamartoma. J Am Acad Dermatol 49:924-929, 2003

3. Bolande RP: The neurocristopathies. A unifying concept of disease arising in neural crest maldevelopment. Hum Pathol 5:409-429, 1974

4. Chakrabortty S, Oi S, Suzuki H, Izawa I, Yamaguchi M, Tamaki N, et al: Congenital frontal bone defect with intact overlying scalp. Childs Nerv Syst 9:485-487, 1993

5. Conrad DM, Chaplin A, Walsh NM, Pasternak S: Extensive neurocristic hamartoma with bone marrow involvement. Am J Dermatopathol 32:486-488, 2010

6. Denlinger CE, Slingluff CL Jr, Mihm MC Jr, Patterson JW: Extensive neurocristic hamartoma with skeletal muscle involvement. J Cutan Pathol 34:634-639, 2007

7. Detwiler PW, Porter RW, Coons SW, Spetzler RF, Carrion CA, Rekate HL: Sporadic unifocal infantile myofibromatosis involving the skull. Case report. J Neurosurg 90:1129-1132, 1999

8. Findler G, Hoffman HJ, Thomson HG, Becker L: Giant nevus of the scalp associated with intracranial pigmentation. Case report. J Neurosurg 54:108-112, 1981

9. Gibson SE, Prayson RA: Primary skull lesions in the pediatric population: a 25-year experience. Arch Pathol Lab Med 131:761-766, 2007

10. Hamilton S, Macrae D, Agrawal S, Matic D: Melanotic neuroectodermal tumour of infancy. Can J Plast Surg 16:4144, 2008

11. Jones HH, Parker BR, Ballerio CG, Silverman FN, Kempson 
RL: Case report 617. Melanotic neuroectodermal tumor of infancy (melanotic progonoma) involving the calvaria. Skeletal Radiol 19:527-530, 1990

12. Kim SK, Kim YC: Neurocristic cutaneous hamartoma of the scalp. Ann Dermatol 21:396-398, 2009

13. Linskey KR, Dias-Santagata D, Nazarian RM, Le LP, Lam Q, Bellucci KSW, et al: Malignant neurocristic hamartoma: a tumor distinct from conventional melanoma and malignant blue nevus. Am J Surg Pathol 35:1570-1577, 2011

14. Marano SR, Brooks RA, Spetzler RF, Rekate HL: Giant congenital cellular blue nevus of the scalp of a newborn with an underlying skull defect and invasion of the dura mater. Neurosurgery 18:85-89, 1986

15. Menter MA, Griessel PJC, DeKlerk DJ: Giant blue naevus of the scalp with underlying skull defect. Br J Dermatol 85:73-75, 1971

16. Micali G, Innocenzi D, Nasca MR: Cellular blue nevus of the scalp infiltrating the underlying bone: case report and review. Pediatr Dermatol 14:199-203, 1997

17. Murali R, McCarthy SW, Scolyer RA: Blue nevi and related lesions: a review highlighting atypical and newly described variants, distinguishing features and diagnostic pitfalls. Adv Anat Pathol 16:365-382, 2009

18. Nakano S, Kinoshita K, Morita Y, Inoue S, Kawana N: Cellular blue nevus of the scalp associated with intracranial involvement. Surg Neurol 27:553-557, 1987

19. Patel S, Rudzinski E, Perkins J: Congenital neurocristic tumor of the head and neck. Laryngoscope 123:805-808, 2013

20. Paueksakon P, Parker JR, Fan X, Miles G, Ruiz H, Wushensky C, et al: Melanotic neuroectodermal tumor of infancy discovered after head trauma. Pediatr Neurosurg 36:33-36, 2002

21. Pearson JP, Weiss SW, Headington JT: Cutaneous malignant melanotic neurocristic tumors arising in neurocristic hamartomas. A melanocytic tumor morphologically and biologically distinct from common melanoma. Am J Surg Pathol 20:665-677, 1996

22. Rodriguez HA, Ackerman LV: Cellular blue nevus. Clinicopathologic study of forty-five cases. Cancer 21:393-405, 1968
23. Silverberg GD, Kadin ME, Dorfman RF, Hanbery JW, Prolo DJ: Invasion of the brain by a cellular blue nevus of the scalp. A case report with light and electron microscopic studies. Cancer 27:349-355, 1971

24. Smith KJ, Mezebish D, Williams J, Elgart ML, Skelton HG: The spectrum of neurocristic cutaneous hamartoma: clinicopathologic and immunohistochemical study of three cases. Ann Diagn Pathol 2:213-223, 1998

25. Turel MK, Chacko G, Raja A, Scheithauer BW: Neurocristic cutaneous hamartoma of the scalp. J Pediatr Neurosci 7:181-184, 2012

26. Tuthill RJ, Clark WH Jr, Levene A: Pilar neurocristic hamartoma: its relationship to blue nevus and equine melanotic disease. Arch Dermatol 118:592-596, 1982

27. Wang JC, Wei L, Xu J, Liu JF, Gui L: Congenital skull defect and neurofibroma: without scalp and other abnormalities. J Craniofac Surg 23:e275-e276, 2012

28. Wetherington GM, Norins AL, Sadove AM: Locally invasive cellular blue nevus of the scalp. Plast Reconstr Surg 79:114-117, 1987

29. Yang CA, Peng SS, Hsieh WS, Tsao PN, Chen CY, Chou HC: Large parietal midline defect with unusual ridge-like structure at the rim and persistent falcine sinus. Childs Nerv Syst 29:1069-1072, 2013

\section{Author Contributions}

Conception and design: Lam. Acquisition of data: Lam, Hadley. Analysis and interpretation of data: Lam, Hadley, Mohila. Drafting the article: Hadley. Critically revising the article: Lam, Mohila. Reviewed submitted version of manuscript: all authors. Approved the final version of the manuscript on behalf of all authors: Lam. Administrative/technical/material support: Lam, Luerssen. Study supervision: Lam.

\section{Correspondence}

Sandi Lam, Department of Neurosurgery, Baylor College of Medicine, Texas Children's Hospital, 6701 Fannin St., CCC Ste. 1230, Houston, TX 77030. email: sklam@texaschildrens.org. 